\title{
CRM1, a novel independent prognostic factor overexpressed in invasive breast carcinoma of poor prognosis
}

\author{
LU YUE $^{1 *}$, ZHEN-NI SUN $^{1 *}$, YA-SAI YAO ${ }^{1}$, ZAN SHEN $^{2}$, HAI-BO WANG ${ }^{3}$, XIANG-PING LIU ${ }^{4}$, \\ FANG ZHOU $^{5}$, JIN-YU XIANG ${ }^{6}$, RU-YONG YAO ${ }^{4}$ and HAI-TAO NIU ${ }^{3}$
}

\author{
${ }^{1}$ Department of Oncology, Qingdao Municipal Hospital, School of Medicine, Qingdao University, Qingdao, \\ Shandong 266003; ${ }^{2}$ Department of Oncology, The Sixth People's Hospital, Medical College of Shanghai Jiao Tong University, \\ Shanghai 200233; ${ }^{3}$ Department of Surgery; ${ }^{4}$ Central Laboratory, The Affiliated Hospital of Qingdao University, \\ Qingdao, Shandong 266003; Departments of ${ }^{5}$ Radiotherapy and ${ }^{6}$ Oncology, Yantai Yuhuangding Hospital \\ Affiliated to Medical College of Qingdao University, Yantai, Shandong 264000, P.R. China
}

Received November 11, 2015; Accepted April 21, 2017

DOI: $10.3892 / 01.2018 .8316$

\begin{abstract}
Breast cancer (BC) is the most commonly diagnosed cancer in females globally and is more aggressive at later stages. Chromosome region maintenance 1 (CRM1) is involved in the nuclear export of proteins and RNAs and has been associated with a number of malignancies. However, the clinicopathological significance of its expression in BC remains to be elucidated therefore this was investigated in the present study. CRM1 expression in 280 breast cancer tissues and 60 normal tissues was retrospectively analyzed using immunohistochemistry (IHC) and western blotting. IHC investigation demonstrated that CRM1 expression was significantly increased in $\mathrm{BC}$ compared with the normal breast epithelium $(\mathrm{P}<0.0001)$. Overexpression of CRM1 was markedly associated with poor prognostic characteristics, including larger tumor size $(\mathrm{P}=0.024)$, positive lymph node metastasis $(\mathrm{P}=0.032)$, invasive histological type $(\mathrm{P}=0.004)$ and distant metastasis $(\mathrm{P}=0.026)$. Significant associations were also observed between increased CRM1 expression and the progesterone receptor $(\mathrm{P}=0.028)$ and $\mathrm{Ki67}(\mathrm{P}=0.019)$. Kaplan-Meier survival analysis demonstrated that patients with high CRM1 expression exhibited a reduced disease-free survival and overall survival compared with those with low
\end{abstract}

Correspondence to: Professor Ru-Yong Yao, Central Laboratory, The Affiliated Hospital of Qingdao University, 16 Jiangsu Road, Qingdao, Shandong 266003, P.R. China

E-mail: yry0303@163.com

Dr Hai-Tao Niu, Department of Surgery, The Affiliated Hospital of Qingdao University, 16 Jiangsu Road, Qingdao, Shandong 266003, P.R. China

E-mail: niuht0532@126.com

${ }^{*}$ Contributed equally

Key words: chromosome region maintenance 1, breast cancer, prognosis
CRM1 expression $(\mathrm{P}=0.013)$. In the multivariate analysis, CRM1 expression $(\mathrm{P}=0.011)$, tumor size $(\mathrm{P}=0.001)$ and lymph node metastasis $(\mathrm{P}<0.001)$ were independent prognostic markers of BC. In conclusion, CRM1 serves an important role in $\mathrm{BC}$ and may serve as a predictive and prognostic factor for a poor outcome in patients with $\mathrm{BC}$.

\section{Introduction}

Breast cancer (BC), which is a heterogeneous disease with numerous molecular profiles, clinical behaviors and responses to therapy, is the most prevalent cancer and predominant cause of cancer-associated mortality in females globally (1). Although stage I-II BC currently exhibits a high average 5 -year survival rate due to a number of antitumor therapies, the continued prevalence of invasion, metastasis and recurrence of the disease remains challenging (2). The TNM (Tumor Node Metastasis) classification (3) of patients with BC establishes a model for accurately predicting patient survival and guiding therapeutic decision-making. However, the considerable heterogeneity of $\mathrm{BC}$ at a molecular level exhibited numerous genetic predispositions and as a result, even patients with early TNM stages and favorable prognoses may experience recurrence and subsequently succumb to the tumor. Therefore, the present study wished to investigate novel genes and their associations with the conventional clinicopathological TNM stage system to improve prognostic stratification and provide potential therapeutic targets for $\mathrm{BC}$.

Chromosome region maintenance 1 (CRM1), also termed exportin $1 / \mathrm{Xpo1}$, was originally identified in the Schizosaccharomyces pombe fission yeast in a screen for genes that are vital for maintaining high-order chromosome structure (4). Previous studies established that it is a member of the importin $\beta$ superfamily of nuclear export receptors (karyopherins) that facilitates the transport of large macromolecules, including RNAs and proteins, across the nuclear membrane to the cytoplasm via nuclear pore complexes $(5,6)$. In addition to nuclear-cytosolic transport, CRM1 also serves a role in centrosome duplication and spindle assembly, particularly in response to DNA damage (7). The transport of macromolecules across 
the nuclear membrane is essential to maintain the appropriate function and homeostasis of a living cell. As the primary nuclear export receptor in humans, CRM1 serves pivotal roles in nuclear protein transport (8). Molecules to be exported may be recognized by CRM1 through a certain leucine-rich nuclear export signal (NES) consensus sequence and may interact with a small guanosine triphosphatase molecule Ras-related nuclear protein (RanGTP) in its guanosine triphosphate (GTP)-bound form, which binds to CRM1 pores with export cargos (9). The CRM1-Ran-GTP complex functions as a solo nuclear transporter for numerous transcription factors and important tumor suppressor proteins, including forkhead box proteins, tumor protein (p)53, nucleophosmin, breast cancer type 1 susceptibility 1 protein, adenomatous polyposis coli protein, survivin, nuclear factor of kappa light polypeptide gene enhancer in B-cells inhibitor, $\alpha$ and others, regulating growth and survival of cancer cells (10-13). Mutations or the dysregulation of these proteins may lead to an imbalance in the cytosolic concentration and prevent these proteins from effectively performing their normal functions within the nucleus, which has been widely observed in cancer cells (14-18). Previous studies have indicated that CRM1 overexpression may be a risk factor associated with tumor size, lymphadenopathy and liver metastasis in pancreatic cancer patients (19). Additionally, the blockage of CRM1 with the specific inhibitor, KPT-185, significantly reduces the viability of non-small cell lung cancer cells, induces these cells to arrest in G1 phase of the cell cycle and promotes apoptosis in a dose-dependent manner (20). However, to date only few studies focused and investigated CRM1 in BC.

In the present study, the expression of CRM1 in BC was examined, aiming to further elucidate the association between CRM1 expression and clinical characteristics, and to investigate whether CRM1 is associated with the prognosis of patients with BC. In addition, the correlation between CRM1 expression and estrogen receptor (ER), progesterone receptor (PR), receptor tyrosine-protein kinase erbB-2 (HER2/neu), p53 and Ki67 was also assessed.

\section{Materials and methods}

Clinical specimens. A total of 280 patients with primary operable invasive breast carcinoma and 60 with benign breast diseases (normal tissues) who underwent surgery at The Affiliated Hospital of Qingdao University (Qingdao, China) between January 2004 and December 2006 were enrolled in the present study. All patients were female and the overall follow-up was calculated from the date of surgery to the date of the last follow-up (January 2013). The median follow-up period was 72 mon (range, 5-100). All specimens were pathologically assessed independently by two pathologists blinded to the clinical data. All patients were $<70$ years old, with a median age of 52.5 years (range, 32-70), who were not administered any treatment prior to surgery. The clinical and pathological data of the patients, including age, menopausal status, tumor size, lymph node metastasis, vascular invasion, local recurrence, histological type and distant recurrence, were obtained from operative and pathological reports. Other parameters, including ER, PR, HER2/neu, p53 and Ki-67 status, were also recorded. The stages of pathological tumor node metastasis (TNM) were established using the 7th American Joint Committee on Cancer
Table I. CRM1 expression levels in BC tissues and normal tissues.

\begin{tabular}{lccc}
\hline $\begin{array}{l}\text { CRM1 } \\
\text { expression }\end{array}$ & $\begin{array}{c}\text { BC tissues } \\
(\mathrm{n}=280)\end{array}$ & $\begin{array}{c}\text { Normal tissues } \\
(\mathrm{n}=60)\end{array}$ & P-value \\
\hline Low & 62 & 58 & $<0.0001$ \\
High & 218 & 2 & \\
\hline
\end{tabular}

$\mathrm{BC}$, breast cancer; CRM1, Chromosome region maintenance 1.

TNM stage (I, II, III, IV) (21). Written informed consent for the use of the resected tumor tissues was obtained from all patients. The present study was approved by the Ethical Committee of the Affiliated Hospital of Qingdao University.

Immunohistochemistry (IHC). IHC was performed according to the standard protocol procedures (22). Briefly, the paraffin-embedded tissue blocks were sectioned in 3- to 4-um slices on slides. Following de-waxing in xylene $(100 \%)$ at $50^{\circ} \mathrm{C}$ 3 times every $10 \mathrm{~min}$ and hydration by graded ethanol dilutions $(100,95,70$ and $60 \%)$, the slides were rinsed in PBS, blocked for 10 min with $3 \%$ hydrogen peroxide to inhibit the endogenous peroxidase activity, washed with PBS and incubated with the rabbit polyclonal anti-CRM1 antibody (cat. no. ab77977; Abcam, Cambridge, MA, USA; 1:33 dilution) overnight at $4^{\circ} \mathrm{C}$. On the following day, the sections were re-heated at $37^{\circ} \mathrm{C}$ for $45 \mathrm{~min}$ and subsequently washed 3 times with PBS for $10 \mathrm{~min}$ followed by an incubation with a PV9000 2-step plus poly-horseradish peroxidase (HRP) anti-mouse/rabbit IgG Detection system (cat. no. PV-9000; Beijing ZSGB-Bio Company, Beijing, China) for a total of $40 \mathrm{~min}$ at $37^{\circ} \mathrm{C}$ in a humid chamber, according to the manufacturer's instruction. The sections were washed 3 times for 3 min with PBS, followed by the addition of 3,3'-diaminobenzidine as a chromogen. Antibodies were optimized using positive control tissue according to the manufacturer's protocol. In the negative controls, the primary antibody was replaced with PBS. Each slide was visualized randomly in 10 fields on an Olympus BX-51 light microscope (Olympus Corporation, Tokyo, Japan) at x200 magnification and was average scored in a blind fashion by 2 pathologists. The overall percentage of positive cells on an immunostained section was determined according to the pattern of intracellular localization. The intensity of the CRM1-specific staining within a tissue section was determined by the percentage of cells with cytoplasm staining. The strength of immunostaining was measured in a semi-quantitative manner. A total of 3 random visual fields were examined and the rates of positive cells were divided into: $<5 \%$, score $0 ; 6-25 \%$, score $1 ; 26-50 \%$, score 2 ; $51-75 \%$, score 3 ; and $>75 \%$, score 4 . The staining intensity was divided into 4 grades: No staining, score 0 ; slightly yellowish, score 1; brownish yellow, score 2; and dark brown, score 3 . The multiplication of the two was graded as follows: 0 , score $0 ; 1+$, score 1-4; 2+, score 5-8; and 3+, score 9-12. Intensity scores of 0 or $1+$ were designated as low expression and $2+$ and $3+$ were designated as high expression.

Western blot analysis. Tissues were lysed in lysis buffer $(20 \mathrm{mM}$ Tris-HCl, 150 mM NaCl, 2 mM EDTA, 1\% Triton X-100, 


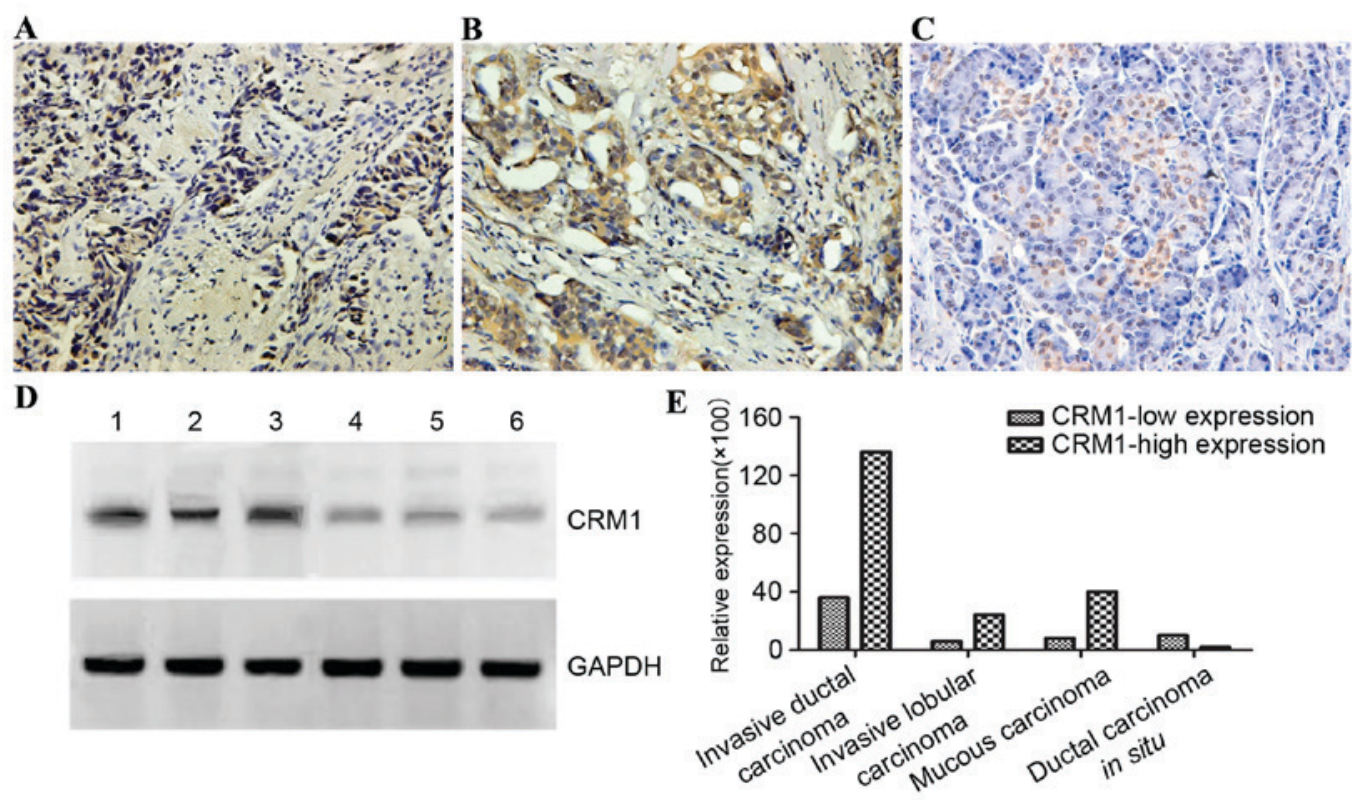

Figure 1. CRM1 expression levels in BC tissues and normal breast tissues. (A-C) Immunohistochemical staining demonstrated CRM1 is primarily expressed in the cytoplasm of BC tissues and normal breast tissues at magnification, x400. (A) Well-differentiated BC tissues. (B) Poorly differentiated BC tissues. (C) Normal breast tissues. (D) Western blot analysis demonstrated CRM1 expression was significantly increased in BC tissues (1-3) compared with normal breast tissues (4-6). (E) Invasive ductal carcinoma demonstrated the highest CRM1 expression level, whilst ductal carcinoma in situ exhibited the lowest CRM1 expression level. BC, breast cancer; CRM1, chromosome region maintenance 1.

and $1 \mathrm{X}$ cocktail protease inhibitors). Total protein from the cell lysate was quantified using the bicinchoninic method (Beyotime Institute of Biotechnology, Haimen, China). A total of $10 \mu \mathrm{l}$ total protein lysates in each lane were separated using 12\% SDS-PAGE and transferred onto nitrocellulose membranes (Whatman; GE Healthcare Life Sciences, Little Chalfont, UK). Western blot analysis was performed using primary antibodies incubation overnight at $4^{\circ} \mathrm{C}$ : CRM1 (1:500; ab77977; Abcam) and GAPDH (1:1,000; sc-32233; Santa Cruz Biotechnology, Inc., Dallas, TX, USA). Primary antibodies was probed with HRP-conjugated secondary antibodies incubated for a further $10 \mathrm{~min}$ at 1:1,000 dilution (NA9310; GE Healthcare Life Sciences). Enhanced chemiluminescence reagents (Santa Cruz Biotechnology, Inc.) were used for detecting the binding antibodies. The ratio of pixel density value of CRM1 was represented by the CRM1/GAPDH grey level ratio under chemiluminescence equipment. The grey level was analyzed using the Quantity One software (Bio-Rad Laboratories, Inc., Hercules, CA, USA).

Statistical analysis. A $\chi^{2}$ test was used to analyze the statistical differences and associations between groups. The overall survival rate was estimated using the Kaplan-Meier method. Cox proportional hazard regression model was used for univariate and multivariate analyses of prognostic values. SPSS v.17.0 software system (SPSS, Inc., Chicago, IL, USA) for was used for statistical analysis. $\mathrm{P}<0.05$ was considered to indicate a statistically significant difference.

\section{Results}

CRM1 expression in BC tissues and normal tissues. CRM1 expression was first assessed by IHC analysis in cancer and normal tissues to ascertain whether the expression of CRM1 is involved in carcinogenesis and clinical progression of BC. CRM1 protein was predominantly located in the cytoplasm in normal tissues (Fig. 1A) and BC tissues (Fig. 1B and C) regardless of tumor differentiation. High levels of CRM1 were observed in $77.86 \%$ (218/280) of the BC cells, whereas the majority of normal tissues exhibited low levels of CRM1 (3.33\%; P<0.0001; Table I). Compared with the reduced CRM1 expression in normal tissues (Fig. 1C), CRM1 expression in $\mathrm{BC}$ tissues increased with disease progression from high levels of differentiation (Fig. 1A) to poor differentiation (Fig. 1B). In accordance with these results, western blot analysis demonstrated that the protein levels of CRM1 were elevated in BC tissues compared with normal tissues (Fig. 1D). The CRM1 antibody recognized an immunoreactive band with a molecular weight of $112 \mathrm{kDa}$. These results indicated that CRM1 expression was increased in BC tissues compared with normal tissues and the enhanced CRM1 expression in $\mathrm{BC}$ is associated with histological progression.

CRM1 expression levels are associated with clinicopathological characteristics. IHC staining of CRM1 was statistically analyzed to determine its association with various clinicopathological characteristics of patients with BC. As demonstrated in Table II, high CRM1 expression was significantly associated with increased tumor size $(\mathrm{P}=0.024)$, positive lymph node metastasis $(\mathrm{P}=0.032)$ and distant metastases $(\mathrm{P}=0.026)$. There were a wide range of CRM1 expression levels within the different pathological types of $\mathrm{BC}$, including invasive ductal carcinoma, invasive lobular carcinoma, mucous carcinoma and ductal carcinoma in situ, and amongst these the most typical BC type to have high expression of CRM1 was invasive ductal carcinoma $(\mathrm{P}=0.004$; Fig. 1E). There was no association identified between CRM1 expression and age, menopausal status, 
Table II. Associations between CRM1 expression levels and clinicopathological characteristics.

\begin{tabular}{|c|c|c|c|c|}
\hline Characteristics & $\mathrm{n}$ & CRM1-low $(n=62)$ & CRM1-high $(n=218)$ & P-value \\
\hline Age, years & & & & 0.171 \\
\hline$<50$ & 106 & 30 & 76 & \\
\hline$>50$ & 174 & 32 & 142 & \\
\hline Menopausal status & & & & 0.901 \\
\hline Premenopausal & 102 & 22 & 80 & \\
\hline Postmenopausal & 178 & 40 & 138 & \\
\hline Tumor size, mm & & & & 0.024 \\
\hline$<20$ & 122 & 38 & 84 & \\
\hline$\geq 20$ & 158 & 24 & 134 & \\
\hline Lymph node metastasis & & & & 0.032 \\
\hline Negative & 142 & 42 & 100 & \\
\hline Positive & 138 & 20 & 118 & \\
\hline Vascular invasion & & & & 0.105 \\
\hline Negative & 118 & 34 & 84 & \\
\hline Positive & 162 & 28 & 134 & \\
\hline Local recurrence & & & & 0.745 \\
\hline Negative & 88 & 18 & 70 & \\
\hline Positive & 192 & 44 & 148 & \\
\hline Histological type & & & & 0.004 \\
\hline Invasive ductal carcinoma & 172 & 36 & 136 & \\
\hline Invasive lobular carcinoma & 30 & 6 & 24 & \\
\hline Mucous carcinoma & 48 & 8 & 40 & \\
\hline Ductal carcinoma in situ & 12 & 10 & 2 & \\
\hline Distant metastases & & & & 0.026 \\
\hline Negative & 166 & 26 & 140 & \\
\hline Positive & 114 & 36 & 78 & \\
\hline
\end{tabular}

CRM1, chromosome region maintenance 1.

vascular invasion or local recurrence (Table II). Additionally, there was a significant association between increased CRM1 expression and $\mathrm{PR}$ negative $(\mathrm{P}=0.028)$ and $\mathrm{Ki} 67$ positive $(\mathrm{P}=0.019)$ status, but not with $\mathrm{ER}, \mathrm{HER} 2 /$ neu and p53 status ( $P>0.05)$, as displayed in Table III.

CRM1 expression levels are associated with survival rates. In order to investigate the prognostic effectiveness of CRM1 levels in patients with BC, the overall survival (OS) and disease-free survival (DFS) and CRM1 expression were compared. Kaplan-Meier analysis demonstrated that the DFS and OS of patients with high CRM1 expression in tumor tissues were significantly reduced compared with those of low CRM1 expression ( $\mathrm{P}=0.013$; Fig. 2A and $\mathrm{B}$ ). The survival rates of patients were significantly associated with tumor size $(\mathrm{P}=0.001)$, lymph node metastasis $(\mathrm{P}=0.005)$ and distant metastases $(\mathrm{P}=0.016)$ assessed using univariate analysis (Table IV). Multivariate Cox proportional hazard analysis revealed that CRM1 expression $(\mathrm{P}=0.011)$, tumor size $(\mathrm{P}=0.001)$ and lymph node metastasis $(\mathrm{P}<0.001)$ were all statistically significant independent prognostic factors for reduced DFS and OS rate.
To additionally explore the effects of CRM1 expression on survival rate, a stage-stratified analysis of tumor size, lymph node metastasis and distant metastasis were performed on the basis of CRM1 expression levels. No difference was observed between DFS as well as OS and CRM1 expression levels between different tumor sizes (Fig. 2C and D). The OS and DFS of patients with lymph node metastasis, distant metastasis and high CRM1 expression were significantly reduced compared with patients with low CRM1 expression levels (Fig. 2E-H).

\section{Discussion}

In the present study, CRM1 expression was assessed in BC tissues and normal tissues by IHC and western blotting to explore whether it may have prognostic value for the management of $\mathrm{BC}$. To the best of our knowledge, this is the first study to identify high CRM1 expression levels as an independent prognostic marker for poor outcome in patients with BC, particularly patients diagnosed with invasive ductal carcinoma. CRM1 expression was markedly higher in BC tissues compared with normal tissues and was associated 
Table III. Associations between CRM1 and ER, PR, HER2/neu and Ki67 status.

\begin{tabular}{|c|c|c|c|c|}
\hline Characteristics & $\mathrm{n}$ & CRM1-low (n=62) & CRM1-high $(\mathrm{n}=218)$ & P-value \\
\hline ER & & & & 0.126 \\
\hline Negative & 98 & 26 & 72 & \\
\hline Positive & 182 & 36 & 146 & \\
\hline PR & & & & 0.028 \\
\hline Negative & 194 & 30 & 164 & \\
\hline Positive & 86 & 32 & 54 & \\
\hline HER 2/neu & & & & 0.594 \\
\hline Negative & 136 & 34 & 102 & \\
\hline Positive & 144 & 28 & 116 & \\
\hline p53 & & & & 0.187 \\
\hline Negative & 180 & 40 & 140 & \\
\hline Positive & 100 & 22 & 78 & \\
\hline Ki67 & & & & 0.019 \\
\hline Negative & 60 & 20 & 40 & \\
\hline Positive & 220 & 42 & 178 & \\
\hline
\end{tabular}

CRM1, chromosome region maintenance 1; ER, estrogen receptor; PR, progesterone receptor; HER2/neu, receptor tyrosine-protein kinase erbB-2; p53, tumor protein 53 .

Table IV. Cox regression analyses of overall survival in patients with breast cancer.

\begin{tabular}{|c|c|c|c|}
\hline Characteristics & $\mathrm{P}$-value & Hazard ratio & $95 \%$ confidence interval \\
\hline \multicolumn{4}{|l|}{ Univariate analysis } \\
\hline Age & 0.654 & 0.647 & $0.756-1.158$ \\
\hline Menopausal status & 0.594 & 0.631 & $0.946-1.368$ \\
\hline Tumor size & 0.001 & 2.165 & $1.695-2.691$ \\
\hline Lymph node metastasis & 0.005 & 2.031 & $1.862-2.435$ \\
\hline Vascular invasion & 0.758 & 1.102 & $0.401-1.157$ \\
\hline Local recurrence & 0.087 & 1.654 & $1.409-2.009$ \\
\hline Histological type & 0.064 & 0.677 & $0.501-0.891$ \\
\hline Distant metastases & 0.016 & 1.256 & $0.765-1.851$ \\
\hline Estrogen receptor & 0.352 & 0.901 & $0.803-1.219$ \\
\hline Progesterone receptor & 0.991 & 1.271 & $0.991-1.687$ \\
\hline Receptor tyrosine-protein kinase erbB-2 & 0.264 & 1.007 & $0.803-1.391$ \\
\hline Tumor protein 53 & 0.871 & 1.040 & $0.669-1.517$ \\
\hline Ki67 & 0.991 & 1.201 & $0.745-1.468$ \\
\hline CRM1 & 0.013 & 1.361 & $1.179-1.603$ \\
\hline \multicolumn{4}{|l|}{ Multivariate analysis } \\
\hline Tumor size & 0.001 & 2.015 & $1.721-2.899$ \\
\hline Lymph node metastasis & 0.001 & 1.992 & $1.730-2.766$ \\
\hline CRM1 & 0.011 & 1.701 & $1.271-2.103$ \\
\hline
\end{tabular}

CRM1, chromosome region maintenance 1.

with tumor size, histological type, lymph node metastasis and distant metastasis. The results of the present study suggested that CRM1 may be an effective biomarker and risk factor in patients for lymph node and distant metastasis. Patients with high CRM1 expression levels could be administered more aggressive therapies.

The prognosis of advanced BC tends to be poor, despite undergoing intensive therapy. Despite the fact that numerous 

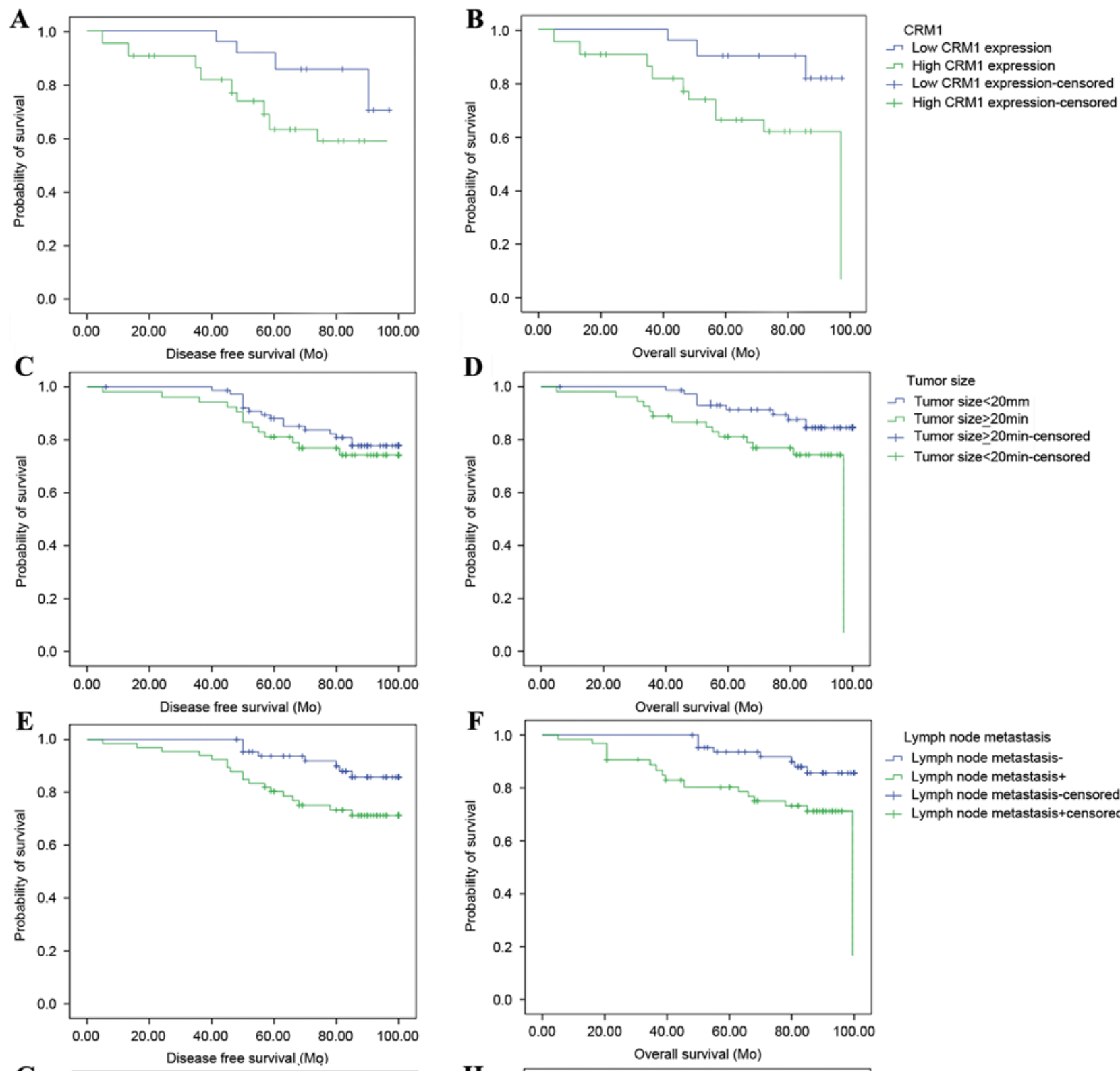

Tumor size

$\rightarrow$ Tumor size $<20 \mathrm{~mm}$

त) Tumor size $>20 \mathrm{~min}$

+ Tumor size $\geq 20 \mathrm{~min}$-censored

+ Tumor size $<20$ min-censored

+

Lymph node metastasis

$\neg$ Lymph node metastasis-

$\rightarrow$ Lymph node metastasis+

+ Lymph node metastasis-censored

+ Lymph node metastasis+censored
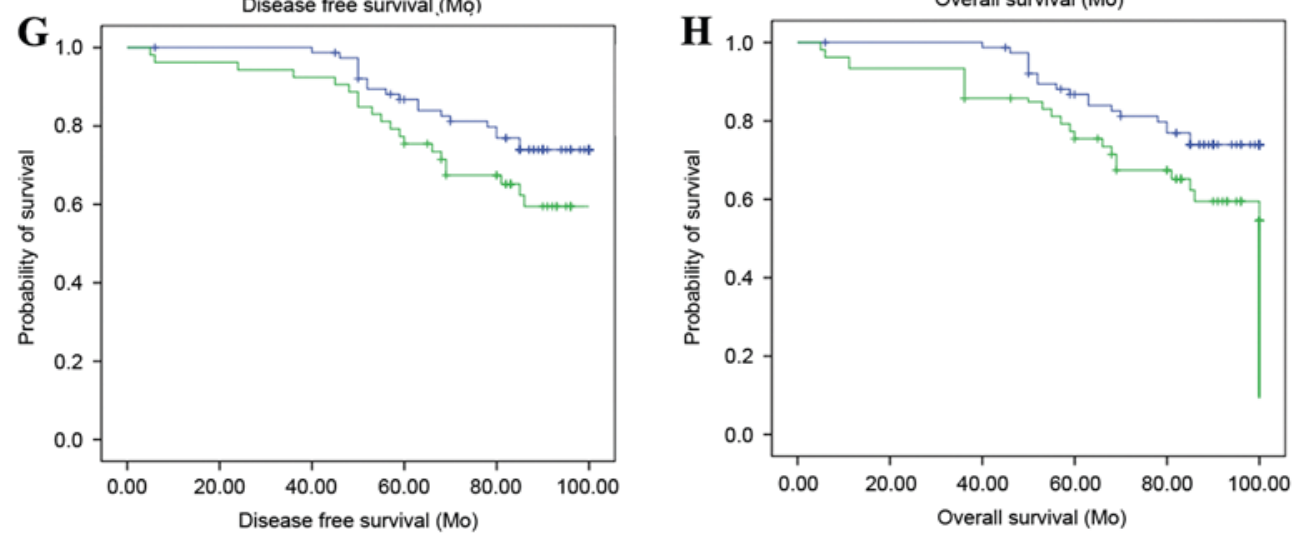

Metastasis

Primary

$\neg$ Metastasis

+ Primary-censored

+ Metastasis-censored

Figure 2. Kaplan Meier survival curves for patients with BC. DFS and OS curves stratified by (A and B) CRM1 expression in BC tissues (high and low expression), (C and D) tumor size $(<20-\geq 20 \mathrm{~mm})$, (E and F) lymph node metastasis (negative or positive) and $(\mathrm{G}$ and $\mathrm{H})$ metastasis status (primary or metastatic). Mo, months; BC, breast cancer; CRM1, Chromosome region maintenance 1.

biomarkers and clinicopathological characteristics, including tumor size, lymph node invasion, distant metastases and expression status of hormonal receptors, have been proposed as prognostic factors for mortality or treatment failure, unfortunately, the clinical significance remains inconsistent and inconclusive. Therefore, novel molecules that identify patients that are likely to have a poor prognosis are required and these may also be used as targeted treatments for patients 
with advanced BC. CRM1 overexpression has been established in a range of solid tumors types, including glioma (23), pancreatic cancer (19), ovarian (24), cervical cancer (25), esophageal cancer (26) and renal carcinoma (27), as well as in hematological malignancies, such as acute myeloid leukemia (AML) (28). Previous studies have demonstrated that the overexpression of CRM1 was significantly associated with poor prognosis in patients with esophageal squamous cell cancer (ESCC), and the silencing of CRM1 promotes apoptosis in ESCC cell lines and inhibits active nuclear factor- $\kappa \mathrm{B}$ signaling (26). The expression of CRM1 in ovarian cancer was identified to be an IHC marker associated with advanced tumor stage and poor differentiation (24). Previous studies from the current study group have demonstrated that CRM1 is an effective indicator of the prognosis in patients with gastric cancer $(29,30)$ and osteosarcoma (31). The present study on $\mathrm{BC}$, in accordance with previous studies, identified that CRM1 expression was increased in $\mathrm{BC}$ compared with normal tissues and predicted a reduced OS and DFS rate.

Considering the fact that numerous molecules lose their function as tumor suppressors through nuclear-cytosolic transport with the aid of CRM1, leaving the cancer cell vulnerable to constitutive growth stimulations and pro-survival signals, it is important to evaluate the role of CRM1 in carcinogenesis. Downregulation of CRM1 using its specific inhibitor KPT-330, demonstrated a dose-dependent cell growth inhibition, promotion of apoptosis and cell cycle arrest in G2/M phase in hepatocellular carcinoma cells. The antitumor activity of KPT-330 has also been demonstrated using in vivo methods (32). The inhibition of CRM1 also induces the upregulation of tumor suppressor p53 and p27, and the downregulation of oncogenes c-Met and c-Myc, indicating its potential role in cancer growth. Furthermore, Gravina et al (33) established that the inhibition of CRM1 impaired the secretion of pro-angiogenic and pro-osteolytic cytokines, and reduced osteoclastogenesis in prostate cancer cells. The results of the present study verified that CRM1 overexpression was associated with an advanced histological grade. In addition, univariate analyses demonstrated that tumor size, lymph node metastasis, distant metastasis and CRM1 expression were significant risk factors affecting DFS and OS rates in patients with BC. In summary, CRM1 may be an independent predictor of poor prognosis in patients with BC. Therefore, the inhibition of CRM1, leading to the nuclear localization, the accumulation and activation of tumor suppressor proteins may be utilized as a novel class of targeted therapies for cancer. However, classical irreversible CRM1 inhibitors, including Leptomycin B (LMB), have demonstrated limited clinical applicability due to severe toxicity and lack of efficacy (34). Subsequently, an increasing number of semi-reversible CRM1 inhibitors, collectively termed as the Selective Inhibitors of Nuclear Export (SINE), have been synthesized (35). SINEs, including KPT-185, KPT-251, KPT-276, KPT-330 and KPT-335, have demonstrated sufficient tolerability in numerous types of solid and hematologic cancer, including pancreas (36), renal (27), multiple myeloma (37), mantle cell leukemia (38), chronic lymphocytic leukemia (39) and AML (40). Therefore, CRM1 inhibitors may be effective novel drugs for targeted treatment of cancer. In conclusion, the present study indicated that CRM1 is a validated predictive marker for poor DFS and OS in patients with BC, and the integration of CRM1 expression into the TNM stage system may provide additional prognostic information. Furthermore, the inhibition of CRM1 expression may be a novel therapeutic strategy for BC.

\section{Acknowledgements}

Not applicable.

\section{Funding}

The present study is supported by National Natural Science Foundation of China (grant no. 81573451).

\section{Availability of data and materials}

All datasets used and/or analyzed during the current study are available from the corresponding author on reasonable request.

\section{Authors' contributions}

LY, ZSu, RY and YY conceived and designed the study. ZSh, HW and XL performed the experiments. HN, FZ and JX analyzed data, and wrote the paper. LY, ZSu and RY reviewed and edited the manuscript. All authors read and approved the final manuscript.

\section{Ethics approval and consent to participate}

Written informed consent for the use of the resected tumor tissues was obtained from all patients. The present study was approved by the Ethical Committee of the Affiliated Hospital of Qingdao University.

\section{Consent for publication}

Patients provided written informed consent for the publication of their data.

\section{Competing interests}

The authors declare that they have no competing interests.

\section{References}

1. Siegel R, Naishadham D and Jemal A: Cancer statistics, 2012. CA Cancer J Clin 62: 10-29, 2012.

2. Bacac M and Stamenkovic I: Metastatic cancer cell. Annu Rev Pathol 3: 221-247, 2008.

3. Singletary SE and Connolly JL: Breast cancer staging: Working with the sixth edition of the AJCC cancer staging manual. CA Cancer Clin 56: 37-47, 2006.

4. Adachi Y and Yanagida M: Higher order chromosome structure is affected by cold-sensitive mutations in a Schizosaccharomyces pombe gene crm1+ which encodes a $115-\mathrm{kD}$ protein preferentially localized in the nucleus and its periphery. J Cell Biol 108: 1195-1207, 1989.

5. Turner JG, Dawson J and Sullivan DM: Nuclear export of proteins and drug resistance in cancer. Biochem Pharmacol 83: 1021-1032, 2012.

6. Fukuda M, Asano S, Nakamura T, Adachi M, Yoshida M, Yanagida M and Nishida E: CRM1 is responsible for intracellular transport mediated by the nuclear export signal. Nature 390: 308-311, 1997. 
7. Arnaoutov A, Azuma Y, Ribbeck K, Joseph J, Boyarchuk Y, Karpova T, McNally J and Dasso M: Crm1 is a mitotic effector of Ran-GTP in somatic cells. Nat Cell Biol 7: 626-632, 2005.

8. Vancurova I and Vancura A: Regulation and function of nuclear $\mathrm{I} \kappa \mathrm{B} \alpha$ in inflammation and cancer. Am J Clin Exp Immunol 1: $56-66,2012$

9. Fornerod M, Ohno M, Yoshida M and Mattaj IW: CRM1 is an export receptor for leucine-rich nuclear export signals. Cell 90 1051-1060, 1997.

10. Brodie KM and Henderson BR: Characterization of BRCA1 protein targeting, dynamics, and function at the centrosome: A role for the nuclear export signal, CRM1, and Aurora A kinase. J Biol Chem 287: 7701-7716, 2012.

11. Chan KS, Wong CH, Huang YF and Li HY: Survivin withdrawal by nuclear export failure as a physiological switch to commit cells to apoptosis. Cell Death Dis 1: e57, 2010.

12. Mariano AR, Colombo E, Luzi L, Martinelli P, Volorio S Bernard L, Meani N, Bergomas R, Alcalay M and Pelicci PG: Cytoplasmic localization of NPM in myeloid leukemias is dictated by gain-of-function mutations that create a functional nuclear export signal. Oncogene 25: 4376-4380, 2006.

13. Henderson BR: Nuclear-cytoplasmic shuttling of APC regulates beta-catenin subcellular localization and turnover. Nat Cell Biol 2: 653-660, 2000.

14. Cunningham MA, Zhu Q and Hammond JM: FoxOla can alter cell cycle progression by regulating the nuclear localization of p27kip in granulosa cells. Mol Endocrinol 18: 1756-1767, 2004.

15. Swamy MV, Herzog CR and Rao CV: Inhibition of COX-2 in colon cancer cell lines by celecoxib increases the nuclear localization of active p53. Cancer Res 63: 5239-5242, 2003.

16. Rexhepaj R, Rotte A, Gu S, Michael D, Pasham V, Wang K, Kempe DS, Ackermann TF, Brücher B, Fend F, et al: Tumor suppressor gene adenomatous polyposis coli downregulates intestinal transport. Pflugers Arch 461: 527-536, 2011.

17. Meens MJ, Sabine A, Petrova TV and Kwak BR: Connexins in lymphatic vessel physiology and disease. FEBS Lett 588 : $1271-1277,2014$

18. de Moura MB, dos Santos LS and Van Houten B: Mitochondrial dysfunction in neurodegenerative diseases and cancer. Environ Mol Mutagen 51: 391-405, 2010.

19. Huang WY, Yue L, Qiu WS, Wang LW, Zhou XH and Sun YJ: Prognostic value of CRM1 in pancreas cancer. Clin Invest Med 32: E315, 2009

20. Wang S, Han X, Wang J, Yao J and Shi Y: Antitumor effects of a novel chromosome region maintenance 1 (CRM1) inhibitor on non-small cell lung cancer cells in vitro and in mouse tumor xenografts. PloS One 9: e89848, 2014

21. Edge SB and Compton CC: The American joint committee on cancer: The 7th edition of the AJCC cancer staging manual and the future of TNM. Ann Surg Oncol 17: 1471-1474, 2010.

22. Manning L, O'Rourke KI, Knowles DP, Marsh SA, Spencer YI, Moffat E, Wells GA and Czub S: A collaborative Canadian-United Kingdom evaluation of an immunohistochemistry protocol to diagnose bovine spongiform encephalopathy. J Vet Diagn Invest 20: 504-508, 2008

23. Shen A, Wang Y, Zhao Y, Zou L, Sun L and Cheng C: Expression of CRM1 in human gliomas and its significance in p27 expression and clinical prognosis. Neurosurgery 65: 153-159, 2009.

24. Noske A, Weichert W, Niesporek S, Röske A, Buckendahl AC, Koch I, Sehouli J, Dietel M and Denkert C: Expression of the nuclear export protein chromosomal region maintenance/exportin 1/Xpol is a prognostic factor in human ovarian cancer. Cancer 112: 1733-1743, 2008.

25. van der Watt PJ, Maske CP, Hendricks DT, Parker MI, Denny L, Govender D, Birrer MJ and Leaner VD: The Karyopherin proteins, crm1 and karyopherin beta1, are overexpressed in cervical cancer and are critical for cancer cell survival and proliferation. Int J Cancer 124: 1829-1840, 2009.
26. Yang X, Cheng L, Yao L, Ren H, Zhang S, Min X, Chen X, Zhang $\mathrm{J}$ and $\mathrm{Li} \mathrm{M}$ : Involvement of chromosome region maintenance 1 (CRM1) in the formation and progression of esophageal squamous cell carcinoma. Med Oncol 31: 155, 2014.

27. Inoue H, Kauffman M, Shacham S, Landesman Y, Yang J, Evans CP and Weiss RH: CRM1 blockade by selective inhibitors of nuclear export attenuates kidney cancer growth. J Urol 189: 2317-2326, 2013

28. Kojima K, Kornblau SM, Ruvolo V, Dilip A, Duvvuri S, Davis RE, Zhang M, Wang Z, Coombes KR, Zhang N, et al: Prognostic impact and targeting of CRM1 in acute myeloid leukemia. Blood 121: 4166-4174, 2013.

29. Zhou F, Qiu W, Yao R, Xiang J, Sun X, Liu S, Lv J and Yue L: CRM1 is a novel independent prognostic factor for the poor prognosis of gastric carcinomas. Med Oncol 30: 726, 2013.

30. Sun X, Qiu J, Qi W, Liu J, Liang J and Qiu W: Expression of CRM1 and Her-2/neu and their clinical significance in gastric cancer. Cancer Cell Res 1: 27-36: 2014.

31. Yao Y, Dong Y, Lin F, Zhao H, Shen Z, Chen P, Sun YJ, Tang LN and Zheng SE: The expression of CRM1 is associated with prognosis in human osteosarcoma. Oncol Rep 21: 229-235, 2009.

32. Zheng Y, Gery S, Sun H, Shacham S, Kauffman M and Koeffler HP: KPT-330 inhibitor of XPO1-mediated nuclear export has anti-proliferative activity in hepatocellular carcinoma. Cancer Chemother Pharmacol 74: 487-495, 2014

33. Gravina GL, Tortoreto M, Mancini A, Addis A, Di Cesare E, Lenzi A, Landesman Y, McCauley D, Kauffman M, Shacham S, et al: XPO1/CRM1-selective inhibitors of nuclear export (SINE) reduce tumor spreading and improve overall survival in preclinical models of prostate cancer (PCa). J Hematol Oncol 7: 46, 2014.

34. Kudo N, Matsumori N, Taoka H, Fujiwara D, Schreiner EP, Wolff B, Yoshida M and Horinouchi S: Leptomycin B inactivates CRM1/exportin 1 by covalent modification at a cysteine residue in the central conserved region. Proc Natl Acad Sci USA 96: 9112-9117, 1999.

35. Parikh K, Cang S, Sekhri A and Liu D: Selective inhibitors of nuclear export (SINE)-a novel class of anti-cancer agents. J Hematol Oncol 7: 78, 2014

36. Azmi AS, Aboukameel A, Bao B, Sarkar FH, Philip PA, Kauffman M, Shacham S and Mohammad RM: Selective inhibitors of nuclear export block pancreatic cancer cell proliferation and reduce tumor growth in mice. Gastroenterology 144 447-456, 2013.

37. Tai YT, Landesman Y, Acharya C, Calle Y, Zhong MY, Cea M, Tannenbaum D, Cagnetta A, Reagan M, Munshi AA, et al: CRM1 inhibition induces tumor cell cytotoxicity and impairs osteoclastogenesis in multiple myeloma: Molecular mechanisms and therapeutic implications. Leukemia 28: 155-165, 2014.

38. Zhang K, Wang M, Tamayo AT, Shacham S, Kauffman M, Lee J, Zhang L, Ou Z, Li C, Sun L, et al: Novel selective inhibitors of nuclear export CRM1 antagonists for therapy in mantle cell lymphoma. Exp Hematol 41: 67-78, 2013.

39. Lapalombella R, Sun Q, Williams K, Tangeman L, Jha S, Zhong Y, Goettl V, Mahoney E, Berglund C, Gupta S, et al: Selective inhibitors of nuclear export show that CRM1/XPO1 is a target in chronic lymphocytic leukemia. Blood 120: 4621-4634, 2012.

40. Ranganathan $\mathrm{P}, \mathrm{Yu} X$, Na C, Santhanam R, Shacham S, Kauffman M, Walker A, Klisovic R, Blum W, Caligiuri M, et al: Preclinical activity of a novel CRM1 inhibitor in acute myeloid leukemia. Blood 120: 1765-1773, 2012.

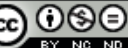

This work is licensed under a Creative Commons Attribution-NonCommercial-NoDerivatives 4.0 International (CC BY-NC-ND 4.0) License. 